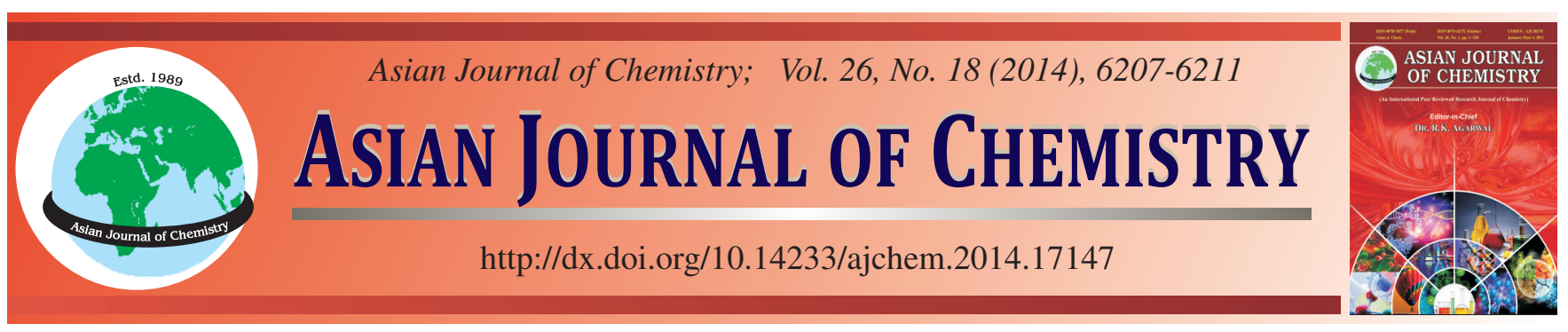

\title{
Conductivity of $\mathrm{Na}_{5}\left[\mathrm{MnCr}\left(\mathrm{OH}_{2}\right) \mathrm{W}_{11} \mathrm{O}_{39}\right] \cdot 14 \mathrm{H}_{2} \mathrm{O}$ Treated by Chemically-Heated Diffusion of Er Permeation
}

\author{
Li-Qiang Chen, Xiu-Mei Lin, Li-Hong Liu, Li-Mei Dai , Ming-Xia Zhu, Wen-Shi Che and Jing Tang
}

Department of Chemistry, Heihe University, Heihe 164300, Heilongjiang Province, P.R. China

*Corresponding author: Tel: +86 15046995938, E-mail: dlm1155@163.com

Received: 30 January 2014;

Accepted: 9 April 2014;

Published online: 1 September 2014;

AJC-15883

\begin{abstract}
The gaseous permeation of erbium into the heteropoly compound $\mathrm{Na}_{5}\left[\mathrm{MnCr}\left(\mathrm{OH}_{2}\right) \mathrm{W}_{11} \mathrm{O}_{39}\right] \cdot 14 \mathrm{H}_{2} \mathrm{O}$ at $540{ }^{\circ} \mathrm{C}$ was performed. The studies of IR and XRD indicate that the keggin structure of the heteropoly compound is destroyed and the main product tungsten bronze $\mathrm{Na}_{0.54} \mathrm{WO}_{3}$ is obtained after permeation. ICP and XPS were used to determine the percentage composition of the erbium in the permeated sample. Conductivity of compounds before and after permeation were investigated by four-electrode method at room temperature and different measuring temperatures, the results reveal that the conductivity of the permeated compound is $10^{5}$ times higher than that of the original compound at room temperature.
\end{abstract}

Keywords: Heteropoly compounds, Tungsten bronzes, Rare earth permeation, Conductivity.

\section{INTRODUCTION}

The heteropoly compounds are important because of their potential applications such as catalysis, biology, magnetism, photochemistry, medicine ${ }^{1-3}$ and good proton conductivity at room temperature ${ }^{4}$. However, when temperature increases, the conductivity of heteropoly compounds will decrease with the number of the crystal water sharply, which greatly impedes their applications in the field of electric function materials. Therefore, it is significantly important to enhance the conductivity of heteropoly compounds at high temperature ${ }^{5-7}$. Recently, our group has successfully permeated the rare earth elements into the heteropoly compounds and their conductivity is significantly enhanced ${ }^{8-11}$. In the present work we describe the gaseous permeation of $\mathrm{Na}_{5}\left[\mathrm{MnCr}\left(\mathrm{OH}_{2}\right) \mathrm{W}_{11} \mathrm{O}_{39}\right] \cdot 14 \mathrm{H}_{2} \mathrm{O}$ by Er at $540{ }^{\circ} \mathrm{C}$. IR spectra, XRD patterns, thermal behaviour and XPS spectra, the conductivity of compounds before and after permeation are investigated.

\section{EXPERIMENTAL}

The infrared spectroscopy (IR) was recorded by $\mathrm{KBr}$ (S.P. grade) pellets on a 1730-FTIR (P.E. U.S.A.) spectrophotometer in the range of 4000-400 $\mathrm{cm}^{-1}$. X-ray diffraction (XRD) patterns were measured using a D/MAX-3C diffractometer with a $\mathrm{Cu}$ target, $\mathrm{K}_{\alpha}$ radiation $(\lambda=0.15405 \mathrm{~nm})$. The elemental analysis was performed by a P1 ASMASPEC (1) ICPAES (Leeman Labs, U.S.A.) quantometer. The X-ray photoelectron spectroscopy (XPS) was executed on an ESCA LAB MARKII XPS spectroscopy.
Thermal analyses before and after permeation were performed on diamond TG-DTA PE thermo-analysis system (U.S.A), respectively. The conductivity was obtained on a KEITHLEY2400 Digital Multimeter (U.S.A.) and a Solartron SI1287 electrochemistry measuring system (U.S.A.). The permeation was performed by RQ3-18-9 crucible cementation furnace. All the reagents used were of analytical reagent (AR) grade.

Preparation of $\mathrm{Na}_{6}\left[\mathrm{MnCr}\left(\mathrm{OH}_{2}\right) \mathrm{W}_{11} \mathrm{O}_{39}\right] \cdot \mathbf{1 4 H}_{2} \mathrm{O}$ : $\mathrm{Na}_{2} \mathrm{WO}_{4} \cdot 2 \mathrm{H}_{2} \mathrm{O}(36.3 \mathrm{~g})$ was dissolved in $200 \mathrm{~mL}$ of water and the $\mathrm{pH}$ of the solution was adjusted to 6.3 with the nitric acid $\left(2 \mathrm{~mol} \mathrm{~L}{ }^{-1}\right)$. After heating this solution to boiling, a mixed solution of $\mathrm{MnSO}_{4} \cdot \mathrm{H}_{2} \mathrm{O}(1.7 \mathrm{~g})$ and $\mathrm{Na}_{2} \mathrm{~S}_{2} \mathrm{O}_{8}(2.3 \mathrm{~g})$ dissolved in $60 \mathrm{~mL}$ of water was added drop wise while stirring. The stirring was continued for $0.5 \mathrm{~h}$ and the temperature was kept at $60{ }^{\circ} \mathrm{C}$. A solution of $\mathrm{Cr}\left(\mathrm{NO}_{3}\right)_{3} \cdot 9 \mathrm{H}_{2} \mathrm{O}(4 \mathrm{~g})$ dissolved in $50 \mathrm{~mL}$ of water was added. In addition, some sodium acetate was added in order to keep the $\mathrm{pH}$ of solution 5, the stirring was continued for $1.5 \mathrm{~h}$ and the temperature was kept at 90$100{ }^{\circ} \mathrm{C}$. The mixture was cooled at room temperature. A brown oily liquid was obtained after adding the absolute alcohol into the above mixture. The brown oily liquid was added the absolute alcohol for several times repeatedly, it turned into fine grained shapes finally and kept in a vacuum desiccators ${ }^{12}$. Yields $12.1 \mathrm{~g}$ (38 \% calculated from $\mathrm{Na}_{2} \mathrm{WO}_{4} \cdot 2 \mathrm{H}_{2} \mathrm{O}$ ). Anal. (by ICP and TG) calcd. (found) (in \%), Na 3.67 (3.66), Mn 1.71 (1.75), W 64.39 (64.44), Cr 1.65 (1.66), $\mathrm{H}_{2} \mathrm{O} 8.69$ (8.61). 
Permeation of Er: According to the method described by $\mathrm{Li}$ et al. ${ }^{8} \cdot \mathrm{Na}_{5}\left[\mathrm{MnCr}\left(\mathrm{OH}_{2}\right) \mathrm{W}_{11} \mathrm{O}_{39}\right] \cdot 14 \mathrm{H}_{2} \mathrm{O}$ was pressed into pellet $(\phi 10 \times 2 \mathrm{~mm})$ with a pressure of $15 \mathrm{MPa}(2 \mathrm{~g})$. The reactant pellet was placed in a RQ3-18-9 crucible cementation furnace with the XMT-101 fine temperature controller. The permeable reagent was self-made ${ }^{13}$. The permeation temperature was $540 \pm 0.5^{\circ} \mathrm{C}$ and permeation lasted for $3 \mathrm{~h}$. Then the sample was cooled cooled to room temperature naturally. Analysis of the permeated sample (by ICP) found (in \%): Er $0.02 \%$.

\section{RESULTS AND DISCUSSION}

IR: Figs. 1 and 2 give IR spectra before and after permeation, respectively. Fig. 1 shows characteristic peaks of the original sample in the range of $1000-400 \mathrm{~cm}^{-1}$. These peaks can be assigned to $v_{\text {as }}(\mathrm{W}=\mathrm{Od}) 938 \mathrm{~cm}^{-1}, v_{\mathrm{as}}(\mathrm{W}-\mathrm{Ob}-\mathrm{W}) 882$ $\mathrm{cm}^{-1}, v_{\text {as }}\left(\right.$ W.Oc-W) $771 \mathrm{~cm}^{-1}, 617 \mathrm{~cm}^{-1}, v_{\text {as }}\left(\right.$ Mn-Oa) $582 \mathrm{~cm}^{-1}$ and $\delta(\mathrm{Oa}-\mathrm{Mn}-\mathrm{Oa}) 420 \mathrm{~cm}^{-1}$, respectively. These data indicate that the compound anions have the Keggin cage structure ${ }^{14}$. Compared with prepermeation (Fig. 2), the frequency of $v_{\text {as }}(\mathrm{W}=\mathrm{Od}), v_{\text {as }}(\mathrm{W}-\mathrm{Oc}-\mathrm{W}), v_{\mathrm{as}}(\mathrm{Mn}-\mathrm{Oa})$ decreased, the main reason is that the permeation of erbium make original skeleton structure destroy and decrease in the stretching vibration frequency. Therefore, it can conclude that chemical bonds exist between erbium and other components of the compound. We can see the original sample has two obvious absorption peaks in 3439 and $1630 \mathrm{~cm}^{-1}$, they are treated as the stretching vibration of O-H bonds and the bending vibration of $\mathrm{H}-\mathrm{O}-\mathrm{H}$ bonds ${ }^{15,16}$, respectively. The permeated sample has two prominent absorption peak in 3437 and $1635 \mathrm{~cm}^{-1}$. These results illustrate that the permeated sample still has water molecules, but the permeated sample has less water molecules than that of the original sample (Fig. 5).

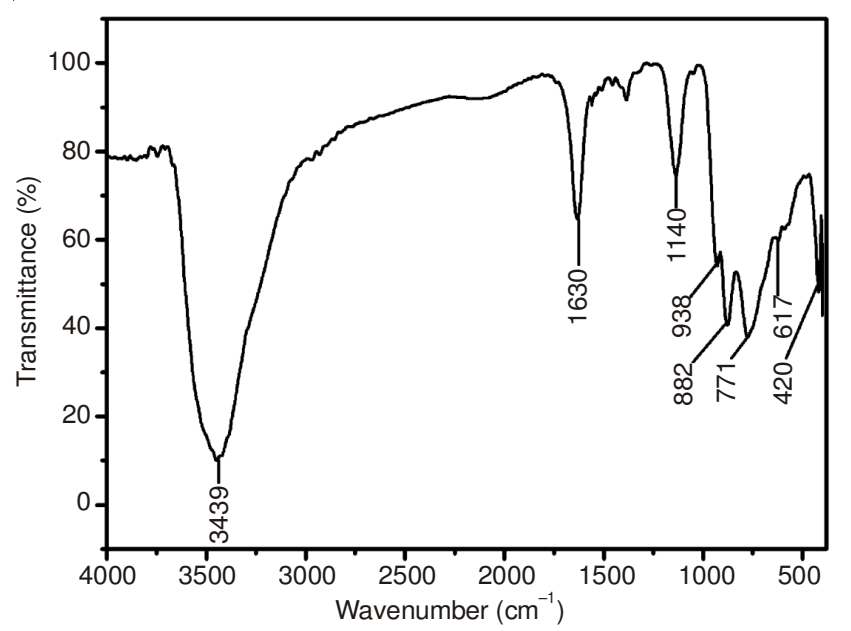

Fig. 1. IR spectrum of the original sample

X-ray diffraction: XRD spectra of compounds before and after permeation are shown in Fig. 3. The original compound has distinct characteristic diffraction peaks at the $2 \theta$ angle of $5^{\circ}-10^{\circ}, 12^{\circ}-15^{\circ}, 18^{\circ}-25^{\circ}, 26^{\circ}-35^{\circ}$ (Fig. $3 \mathrm{~A}$ ), it can be considered that anions of the original compound have the Keggin structure ${ }^{17}$. The permeated compound have different intensities and the positions of the peaks from the original compound, its char

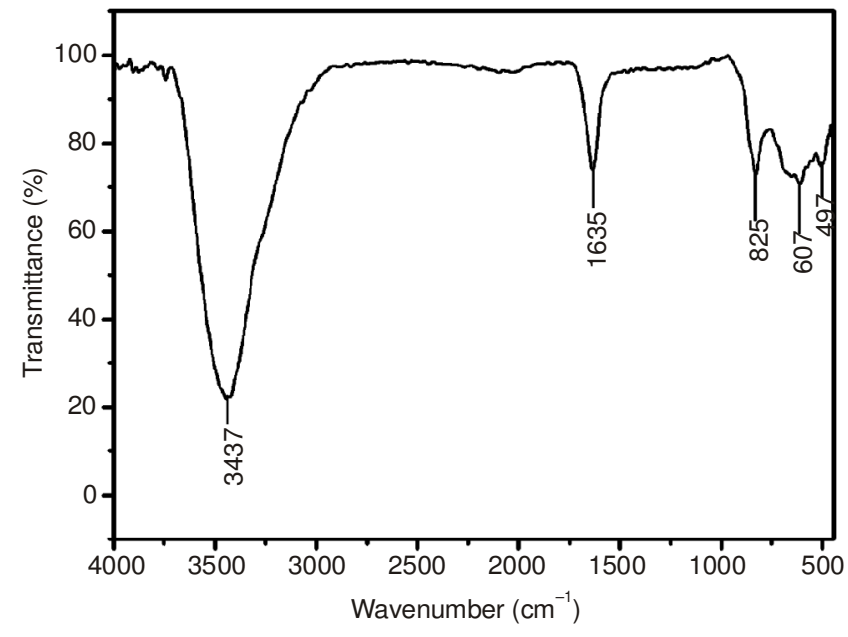

Fig. 2. IR spectrum of the permeated sample

acteristic diffraction peak at the band of $12-15^{\circ}$ disappeared and the new diffraction peaks in the range of $36-69^{\circ}$ are observed (Fig. 3B), those data indicate the Keggin cage structure is destroyed and new phases formed ${ }^{18}$. The result is accordant with the analysis of IR spectrum (Fig. 2). The characteristic peaks of $\mathrm{Na}_{0.54} \mathrm{WO}_{3}$ at the $2 \theta$ angle of $23^{\circ}, 33^{\circ}, 41^{\circ}, 48^{\circ}, 53^{\circ}$, $59^{\circ}, 69^{\circ}$ are observed. In addition, the colour of the permeated sample is red with metallic lustre and the original sample is brown, these results can verify that the main product is $\mathrm{Na}_{0.54} \mathrm{WO}_{3}$ (PDF\#: 75-0294) after permeation.

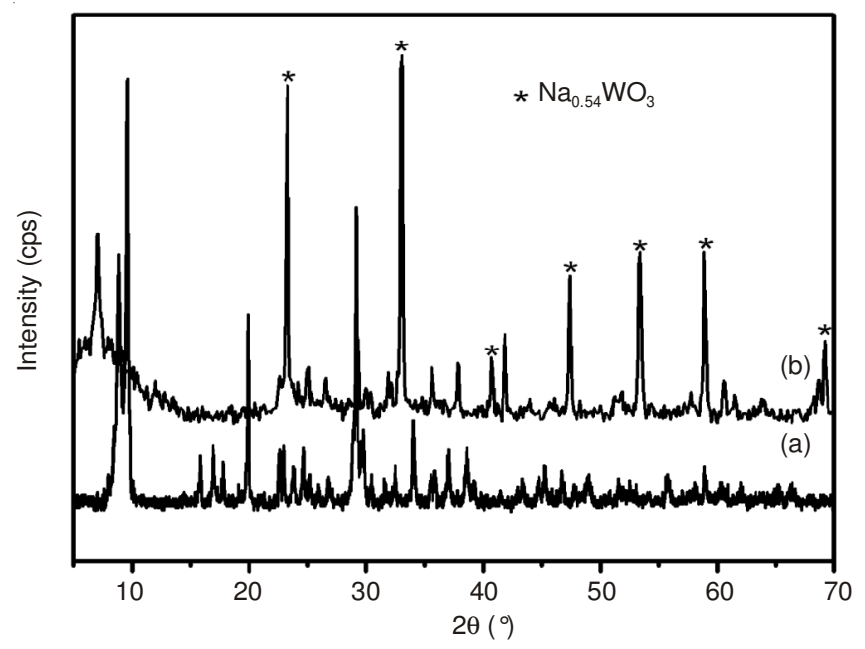

Fig. 3. XRD patterns of compounds before and after permeation of erbium: (a) original sample; (b) permeated sample

Thermal stability: TG-DTA curves of compounds before and after permeation can be observed in Figs. 4 and 5, respectively. The TG curve shows that the total weight loss is 8.64 $\%$, which illustrates that there are three steps of weight loss. The first is the loss of 6 molecules of zeolite water from room temperature to $100{ }^{\circ} \mathrm{C}$, it is consistent with the strong endothermic peaks in the DTA curve; the second is the loss of 8 molecules of composition water from 100 to $412{ }^{\circ} \mathrm{C}$; the third is the loss of 1 molecule of structural water from 412 to $478^{\circ} \mathrm{C}$. Furthermore, a strong exothermic peak appears at $478^{\circ} \mathrm{C}$ in the DTA curve, which is considered to be the decomposition temperature of the original compound ${ }^{19}$. A prominent endothermic 
peak appears at $707^{\circ} \mathrm{C}$ in the DTA curve which indicates the decomposition product melted. The permeation temperature is controlled at $540{ }^{\circ} \mathrm{C}$, which is lower than the melting point to ensure the accomplishment of the permeating process. Thermogravimetric curve of the permeated sample shows that there are a little water molecules and the process of lost water fast. It indicates that the water molecules of the permeated sample are adsorbed water. In the

DTA curve of the permeated sample, there is an exothermic peak at $445^{\circ} \mathrm{C}$, which can be due to the decomposition temperature of the permeated sample. Thermogravimetric curve of the permeated sample shows that there is weight gain after $366^{\circ} \mathrm{C}$, the process of weight gain fast and continuous, which is caused by some lowvalent metallic ions, such as $\mathrm{W}^{5+}, \mathrm{W}^{2+}$, are oxidized by oxygen in the air.

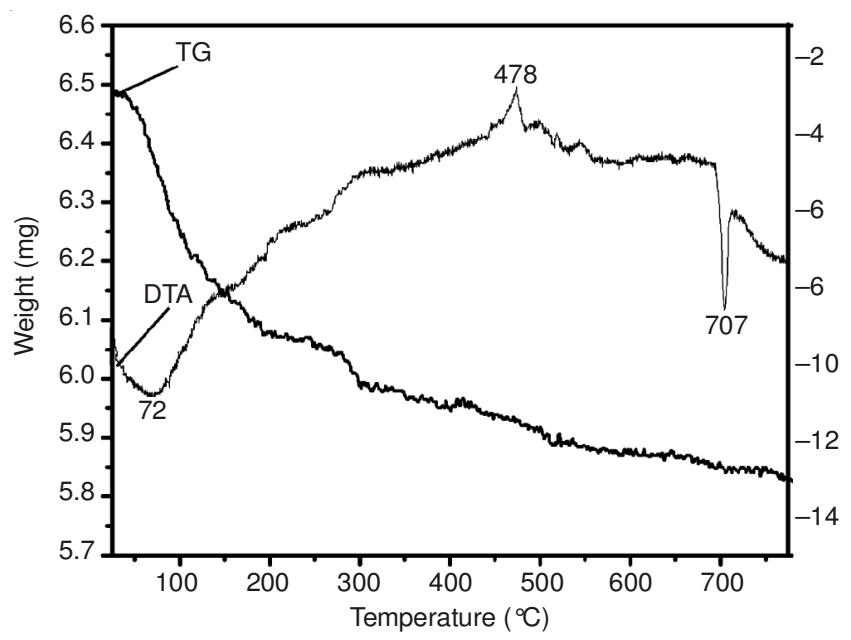

Fig. 4. TG-DTA curve of the original sample

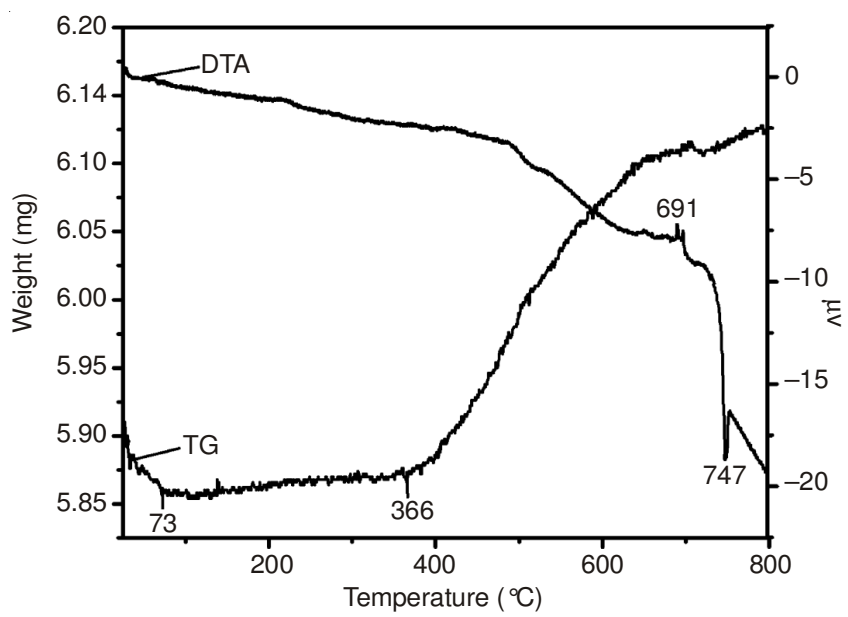

Fig. 5. TG-DTA curve of the permeated sample

XPS: XPS is one of common techniques on the surface analysis, which can determine the elements of the materials and also can give the information of the elements' chemical states $^{20}$. To understand the chemical state of the elements consisting of the samples, XPS analysis was conducted on the samples before and after permeation. The binding energy of Er4d in the permeated sample is $168.7 \mathrm{eV}$ (Fig. 6), it is $0.2 \mathrm{eV}$ higher than the binding energy of the reactant $\mathrm{Er}_{2} \mathrm{O}_{3}$ that is
$168.5 \mathrm{eV}$, which implies that erbium exists in the compound and erbium interacts with the other components of the compound. Moreover, as shown in Fig.7, the binding energy of the oxygen ions of the permeated sample decreases 0.38 $\mathrm{eV}$ than that of the original sample. According to above investigations of IR and XRD, the bond of W-O-W is broken, which leads to the valence shell electron cloud density of the $\mathrm{O}$ ions increase. It is concluded that a part of the external charges of $\mathrm{O}$ ions transfer to erbium ions, the atomic orbits of $\mathrm{O}$ and $\mathrm{Er}$ interlap by transferring the charges and the chemical bond is formed ${ }^{9}$. Figs. 8 and 9 present the XPS spectra of W4f for the samples before and after permeation. W4f electron peak of $\mathrm{W}^{6+}$ state was located at 35.1 and $37.2 \mathrm{eV}$ in the original sample ${ }^{21}$. However, the states of $\mathrm{W}$ in the permeated sample indicate that $\mathrm{W}$ has not only $\mathrm{W}^{6+}$ but also $\mathrm{W}^{5+}$ and $\mathrm{W}^{2+22}$, which can indicate that the keggin structure of the heteropoly compound is destroyed and tungsten bronze $\mathrm{Na}_{0.54} \mathrm{WO}_{3}$ is obtained after permeation. Sodium tungsten bronze $\mathrm{Na}_{\mathrm{x}} \mathrm{WO}_{3}$ may show the presence of tungsten in three discrete valences: $+4,+5$ and $+6^{23}$. It is interesting that $\mathrm{Na}_{0.54} \mathrm{WO}_{3}$ shows the presence of tungsten in three discrete valences: $+2,+5$ and +6 , which could be due to the different synthesis methods. In our synthesis process,

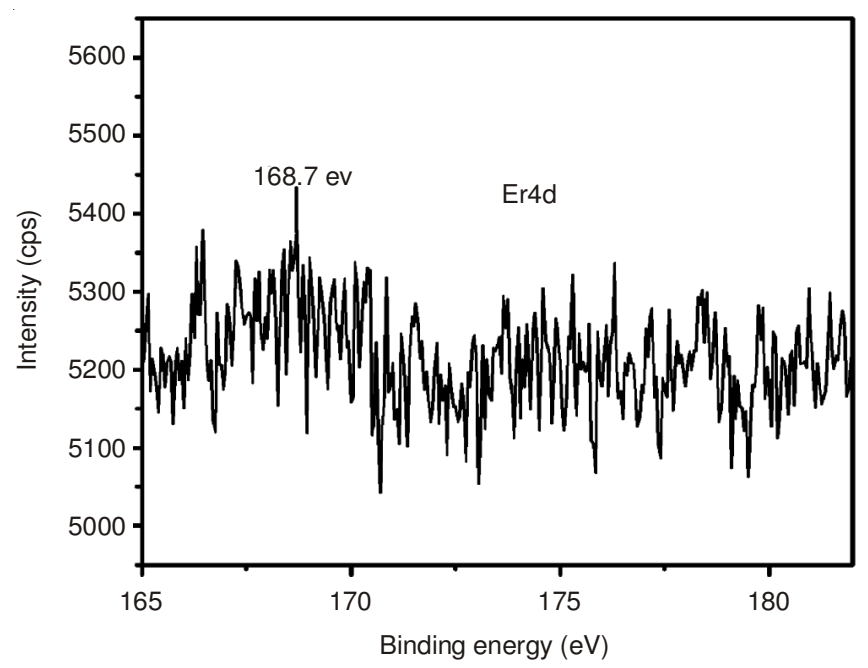

Fig. 6. XPS spectra of Er $4 \mathrm{~d}$ of the permeated sample

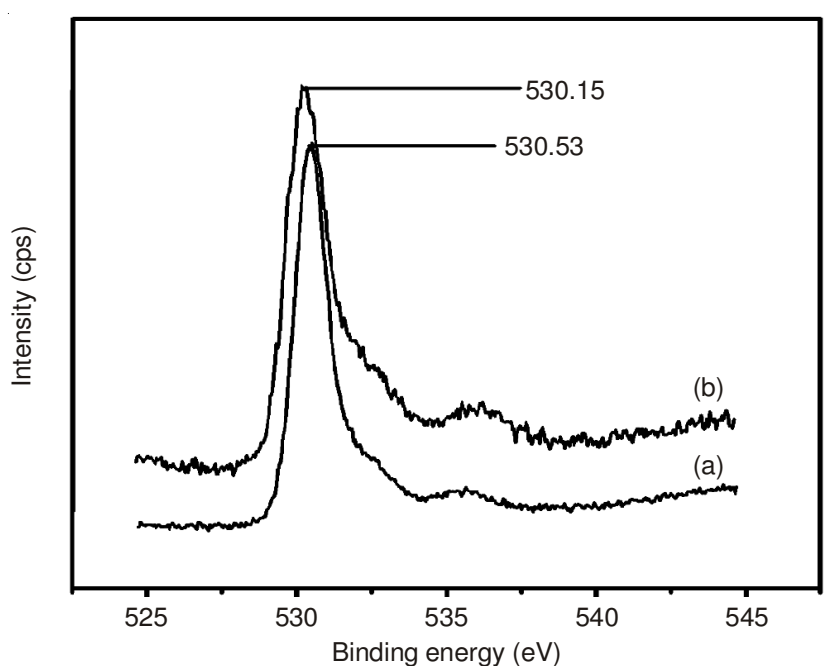

Fig. 7. XPS spectra of O1s of compounds before and after permeation: (A) O1s of the original sample; (B) O1s of the permeated sample 


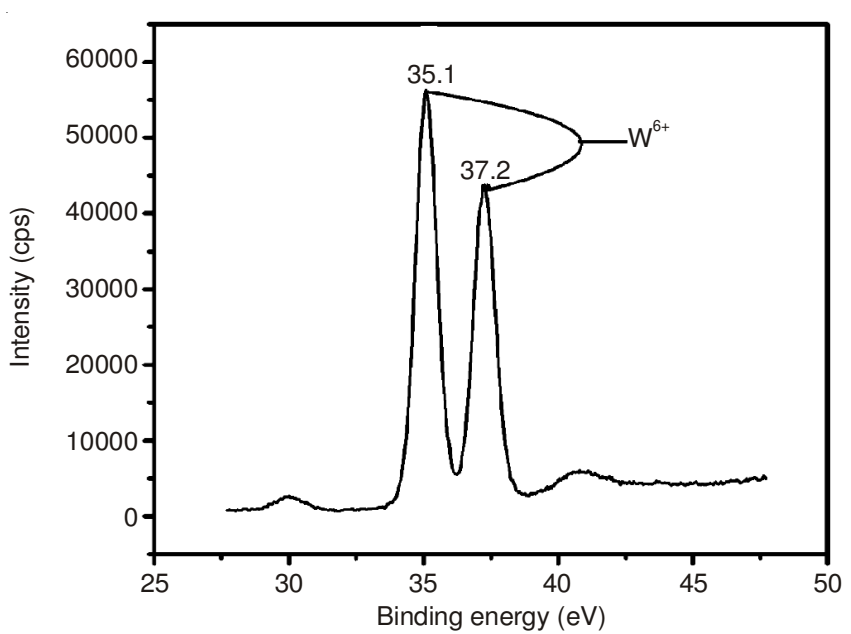

Fig. 8. XPS spectra of W4f of the original sample

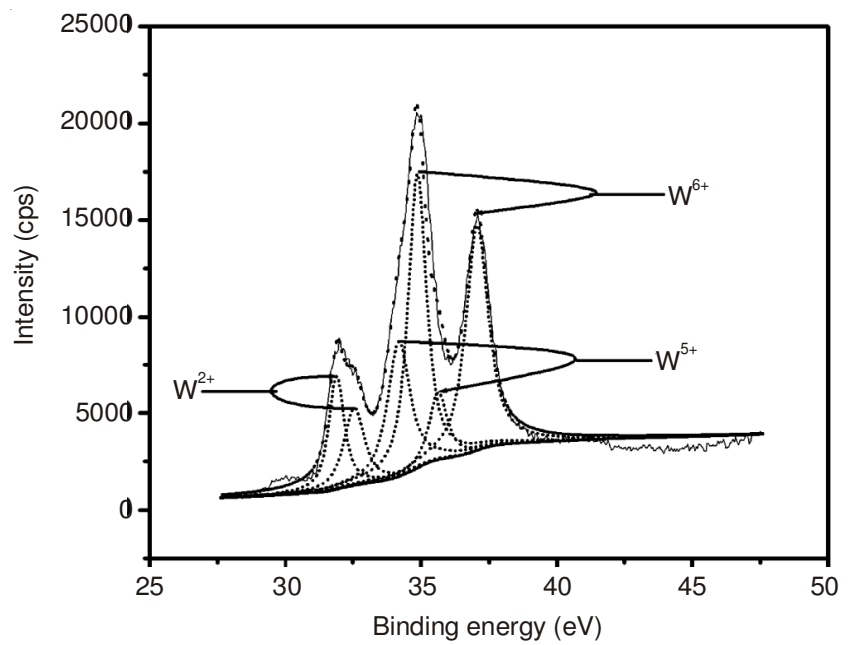

Fig. 9. XPS curve fitting of the W4f of the permeated sample

formamide $\left(\mathrm{HCONH}_{2}\right)$ was one of main compositions in the permeable reagent, $\mathrm{HCONH}_{2}$ begins to partially decomposed from $180{ }^{\circ} \mathrm{C}: \mathrm{HCONH}_{2} \rightarrow \mathrm{CO}+\mathrm{NH}_{3} ; 2 \mathrm{CO} \rightarrow \mathrm{CO}_{2}+[\mathrm{C}]$; $2 \mathrm{NH}_{3} \rightarrow 3 \mathrm{H}_{2}+2[\mathrm{~N}]$. In the reduction atmosphere, hexavalent tungsten can be reduced into low valent tungsten by [C] or $\mathrm{H}_{2}$, Therefore, it is reasonable the permeated main product $\mathrm{Na}_{0.54} \mathrm{WO}_{3}$ show the presence of tungsten in three discrete valences: $\mathrm{W}^{2+}, \mathrm{W}^{5+}$ and $\mathrm{W}^{6+}$.

Electrical conductivity: Electrical conductivity of compounds before and after permeation were measured by four probe method under the same condition. The electric conductivities of the original and permeated samples are $\sigma=2.97 \times$ $10^{-7} \mathrm{~S} \mathrm{~cm}^{-1}$ and $\sigma=1.88 \times 10^{-2} \mathrm{~S} \mathrm{~cm}^{-1}$ respectively at room temperature. The conductivity of the compound after permeation is about $10^{5}$ times higher than that of the original compound, which proves that the electrical conductivity of this compound is significantly enhanced.

To our best of knowledge, the heteropoly compound $\mathrm{Na}_{5}\left[\mathrm{MnCr}(\mathrm{OH})_{2} \mathrm{~W}_{11} \mathrm{O}_{39}\right] \cdot 14 \mathrm{H}_{2} \mathrm{O}$ is the proton conductor and the conductivity of the compound depends on the number of crystal water molecules, the electric resistance of the permeated sample was measured only at different measuring temperatures. The electric resistance of the permeated sample was measured in the temperature range from 27 to $500^{\circ} \mathrm{C}$ (Fig. 10). We see the electric resistance of the permeated sample gradually decease with the increase of temperature from 27 to $359{ }^{\circ} \mathrm{C}$. The electronegativity of erbium is relatively small and the binding affinity to oxygen is very high. The binding of erbium to oxygen is easy when the temperature rises, In this case, a lot of vacancies of oxygen are produced and increase with the temperature increasing, which make the electric resistance of the permeated sample gradually decease. However, when the temperature rises up to $359{ }^{\circ} \mathrm{C}$, the electric resistance sharply increases. As discussed in TG-DTA analysis, the permeated sample begins to gain weight from $366^{\circ} \mathrm{C}$, as mentioned above, oxidation of low valent tungsten back to the $\mathrm{W}^{6+}$ state. This involves removal of electrons from the conduction band of $\mathrm{Na}_{0.54} \mathrm{WO}_{3}$ and lead ultimately to a non-conducting material ${ }^{24,25}$, for the reason that, the electric resistance of this sample increased. In Fig. 11, the conductivity of this sample is intrinsic conductivity between 27 and $146^{\circ} \mathrm{C}$. The changes of the electrical conductivity with the increased temperatures (Table-1) meet the Arrhenius equation $\ln \sigma=-\mathrm{Ea} / \mathrm{RT}^{26}$. By using a curve-fitting algorithm, the activation energy (Ea) of the permeated sample is $0.56 \mathrm{~kJ} \mathrm{~mol}^{-1}$ and thus it is consistent with it has relatively high conductivity.

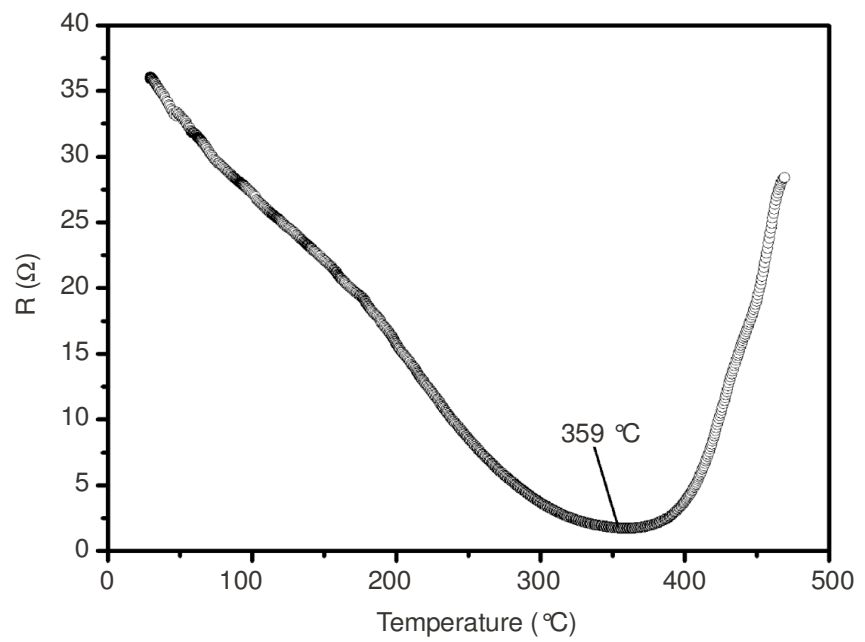

Fig. 10. Electric resistance of the permeated sample at different temperatures

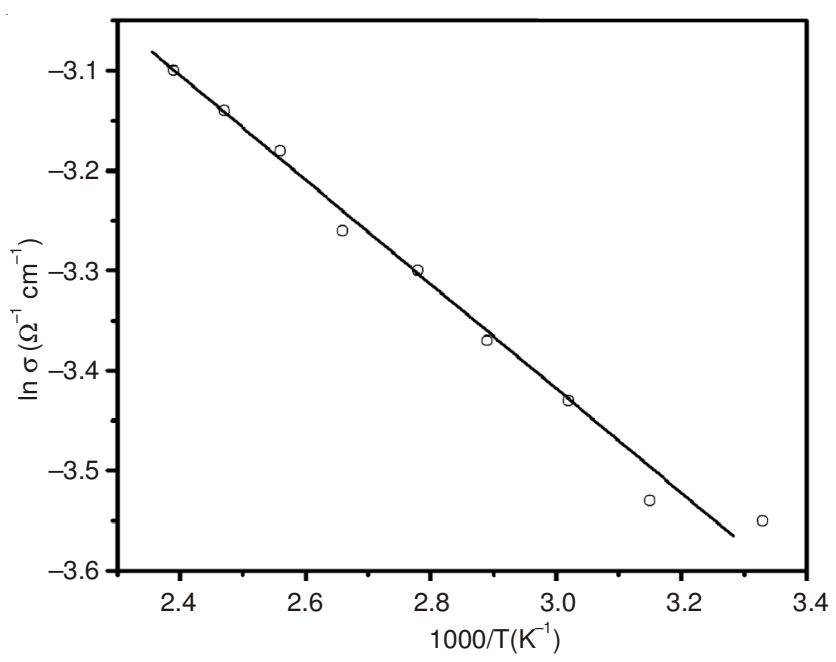

Fig. 11. Arrhenius plot for the permeated sample 


\begin{tabular}{crrrrrrrrr}
\hline \multicolumn{10}{c}{ TABLE-1 } \\
\multicolumn{10}{c}{ CONDUCTIVITY OF THE PERMEATED SAMPLE AT DIFFERENT TEMPERATURES } \\
\hline $\mathrm{T}(\mathrm{K})$ & 300 & 317 & 331 & 346 & 360 & 376 & 390 & 405 & 419 \\
\hline$\sigma\left(\times 10^{-2} \mathrm{~S} \mathrm{~cm}^{-1}\right)$ & 2.88 & 2.94 & 3.23 & 3.45 & 3.70 & 3.83 & 4.14 & 4.31 & 4.50 \\
$\ln \sigma$ & -3.55 & -3.53 & -3.43 & -3.37 & -3.30 & -3.26 & -3.18 & -3.14 & -3.10 \\
$1000 / \mathrm{T}$ & 3.33 & 3.15 & 3.02 & 2.89 & 2.78 & 2.66 & 2.56 & 2.47 & 2.39 \\
\hline
\end{tabular}

\section{Conclusion}

In the present work, we report gaseous permeation of erbium to $\mathrm{Na}_{5}\left[\mathrm{MnCr}\left(\mathrm{OH}_{2}\right) \mathrm{W}_{11} \mathrm{O}_{39}\right] \cdot 14 \mathrm{H}_{2} \mathrm{O}$ for the synthesis of tungsten bronzes $\mathrm{Na}_{0.54} \mathrm{WO}_{3}$. The characteristics results show that there is trace erbium in the permeated sample and erbium interacts with the other components of the compound; the conductivity of the permeated sample is greatly enhanced in comparison with the original compound and it is worthy to note that the conductivity of the permeated sample increases with rise in temperature before $359{ }^{\circ} \mathrm{C}$, getting rid of the conductivity of $\mathrm{Na}_{5}\left[\mathrm{MnCr}-\left(\mathrm{OH}_{2}\right) \mathrm{W}_{11} \mathrm{O}_{39}\right] \cdot 14 \mathrm{H}_{2} \mathrm{O}$ depends on the number of crystal water molecule. In addition, the present research provides a new method to prepare tungsten bronzes.

\section{ACKNOWLEDGEMENTS}

The authors expressed their thanks to the Science and Technology Foundation Office of Education of Heilongjiang Province (No. 12521360).

\section{REFERENCES}

1. L.C.W. Baker and D.C. Glick, Chem. Rev., 98, 3 (1998).

2. P. Gouzerh and A. Proust, Chem. Rev., 98, 77 (1998).

3. P.J. Hagrman, R.C. Finn and J. Zubieta, Solid State Sci., 3, 745 (2001).

4. E.B. Wang, Introduction of Polyacid Chemistry, Chemical Industry Press, Beijing, edn 2 (1998).
5. D.E. Katsoulis, Chem. Rev., 98, 359 (1998).

6. B.B. Zhou, H.Y. Ma and Y.H. Wang, J. Chin. Rare Earth Soc., 19, 393 (2001).

7. Q.Y. Wu, Mater. Lett., 50, 78 (2001).

8. B.B. Zhou, Y.D. Wei and Z.H. Li, J. Chin. Rare Earth Soc., 20, 83 (2002).

9. Z.H. Li, Y.D. Wei, B.B. Zhou and J.F. Wang, J. Rare Earths, 21, 697 (2003).

10. L.L. Wang, B.B. Zhou, J.J. Cao and Y.P. Wang, J. Alloys Comp., 432, 55 (2007).

11. Y.P. Wang, B.B. Zhou and Y.L. Liu, J. Alloys Comp., 463, 333 (2008).

12. L. Li, Y.D. Wei and B.B. Zhou, J. Rare Earths, 21, 113 (2005).

13. Y.D. Wei, N. Ma and Y.L. Hou, J. Rare Earths, 19, 214 (2001).

14. W. Qingyin, W. Enbo and L. Jingfu, Polyhedron, 12, 2563 (1993).

15. V.P. Tolstoy, L.B. Gulina, G.S. Korotchenkov and V.I. Brynsari, Appl. Surf. Sci., 221, 197 (2004).

16. Q.Y. Wu and G.Y. Meng, Mater. Res. Bull., 35, 85 (2000).

17. Z.H. Li and Y.D. Wei, Chin. J. Inorg. Chem., 19, 1053 (2003).

18. X. Li, Z.H. Li and Y.D. Huang, Chin. J. Inorg. Chem., 19, 299 (2003).

19. Q.Y. Wu, X.G. Sang, Y.C. He and X. Li, Mater. Lett., 57, 4028 (2003).

20. P. Datta, P. Majewski and F. Aldinger, Mater. Res. Bull., 43, 1 (2008).

21. P. Biloen and G.T. Pott, J. Catal., 30, 169 (1973).

22. I.G. Casella and M. Contursi, Electrochim. Acta, 588, 147 (2006).

23. B.A. De Angelis and M. Schiavello, Chem. Phys. Lett., 38, 155 (1976).

24. I. Chaitanya Lekshmi and M.S. Hegde, Mater. Res. Bull., 40, 1443 (2005).

25. F.H. Potter and R.G. Egdell, J. Mater. Chem., 4, 1647 (1994).

26. A.S. Nowick, in eds.: G.E. Murch and A.S. Nowick, Diffusion in Crystalline Solids, Academic Press, Wiley-Interscience: New York, edn 1 (1984). 